\title{
Serial echocardiographic left ventricular ejection fraction measurements: A tool for detecting thalassemia major patients at risk of cardiac death
}

\author{
Aurelio Maggio a,c,* , Angela Vitrano ${ }^{\mathrm{b}, \mathrm{c}}$, Giuseppina Calvaruso ${ }^{\mathrm{a}, \mathrm{c}}$, Rita Barone ${ }^{\mathrm{a}, \mathrm{c}}$, Paolo Rigano ${ }^{\mathrm{a}, \mathrm{c}}$, \\ Luigi Mancuso $^{\text {c,d }}$, Liana Cuccia ${ }^{\text {c,e }}$, Marcello Capra ${ }^{\text {c,e }}$, Lorella Pitrolo ${ }^{\text {c,f }}$, Luciano Prossomariti ${ }^{\text {c,g }}$, \\ Aldo Filosa ${ }^{c, h}$, Vincenzo Caruso ${ }^{c, i}$, Calogera Gerardi ${ }^{c, j}$, Saveria Campisi ${ }^{c, k}$, Paolo Cianciulli ${ }^{c, l}$, \\ Arintaya Phrommintikul ${ }^{\mathrm{c}, \mathrm{r}}$, Nipon Chattipakorn ${ }^{\mathrm{c}, \mathrm{r}}$ \\ a U.O.C. Ematologia II, AOR Villa Sofia-V. Cervello, Palermo, Italy \\ ${ }^{\mathrm{b}}$ Dipartimento di Scienze Statistiche e Matematiche 'S. Vianelli', Università di Palermo, Italy \\ ${ }^{c}$ U.O.C. Medicina Trasfusionale, AOR Villa Sofia-V. Cervello, Palermo, Italy \\ d Fondazione Franco e Piera Cutino, Palermo, Italy \\ e U.O.C. Centro di Prevenzione Diagnosi e Cura della Talassemia, ARNAS Civico, Di Cristina, Benfratelli, Palermo, Italy \\ ${ }^{\mathrm{f}}$ U.O.C. Pediatria II, AOR Villa Sofia-V. Cervello, Palermo, Italy \\ g Centro Regionale per la Cura delle Microcitemie, A.O. Cardarelli, Napoli, Italy \\ ${ }^{h}$ U.O.C. Pediatria A.O. Cardarelli, Napoli, Italy \\ i U.O.D. Talassemia, P.O.S. Luigi Currò, ARNAS Garibaldi, Catania, Italy \\ ${ }^{j}$ U.O.S. Talassemia, A.O.O.C.R., Sciacca, Italy \\ ${ }^{k}$ U.O.S. Centro Microcitemia, A.O. Umberto I, Siracusa, Italy \\ ${ }^{1}$ U.O.D. Talassemia, A.O.S. Eugenio, Roma, Italy \\ $\mathrm{m}$ Centro Microcitemia A.O. Perrino, Brindisi, Italy \\ n Thalassemia International Federation, Nicosia, Cyprus \\ ${ }^{\circ}$ Department of Pediatric Cardiology, Cairo University, Egypt \\ ${ }^{\mathrm{p}}$ Department of Paediatric Haematology and Oncology, St. Bartholomew's and The Royal London Hospitals NHS Trust, London, United Kingdom \\ q Royal Brompton and Harefield NHS Trust, London, United Kingdom \\ ${ }^{\mathrm{r}}$ Cardiac Electrophysiology Research and Training Center, Faculty of Medicine, Chiang Mai University, Thailand
} Androulla Elefteriou c,m,n , Michel Angastiniotis ${ }^{c, m, n}$, Hala Hamza ${ }^{c, o}$, Paul Telfer ${ }^{c, p}$, John Malcolm Walker ${ }^{\text {c, q, }}$

\section{A R T I C L E I N F O}

\section{Article history:}

Submitted 17 October 2012

Revised 2 December 2012

Available online 20 January 2013

(Communicated by G. Stamatoyannopoulos, M.D., Dr. Sci., 03 December 2012)

\section{Keywords:}

Thalassemia major

Left ventricular ejection fraction (LVEF)

Chelation

Echocardiography

Cardiac magnetic resonance

$\mathrm{T} 2 *$

\begin{abstract}
A B S T R A C T
Cardiac damage remains a major cause of mortality among patients with thalassemia major. The detection of a lower cardiac magnetic resonance T2* (CMR-T2*) signal has been suggested as a powerful predictor of the subsequent development of heart failure. However, the lack of worldwide availability of CMR-T2* facilities prevents its widespread use for follow-up evaluations of cardiac function in thalassemia major patients, warranting the need to assess the utility of other possible procedures. In this setting, the determination of left ventricular ejection fraction (LVEF) offers an accurate and reproducible method for heart function evaluation. These findings suggest a reduction in $\mathrm{LVEF} \geq 7 \%$, over time, determined by 2 -D echocardiography, may be considered a strong predictive tool for the detection of thalassemia major patients with increased risk of cardiac death. The reduction of $L V E F \geq 7 \%$ had higher (84.76\%) predictive value. Finally, Kaplan-Meier survival curves of thalassemia major patients with LVEF $\geq 7 \%$ showed a statistically significant decreased probability of survival for heart disease $(p=0.0022)$.

However, because of limitations related to the study design, such findings should be confirmed in a large long-term prospective clinical trial.
\end{abstract}

(c) 2012 Elsevier Inc. All rights reserved.

\section{Introduction}

Thalassemia is one of the most common genetic diseases worldwide, with at least 60,000 severely affected subjects being born every year [1].

\footnotetext{
* Corresponding author at: U.O.C. “Ematologia II con Talassemia”, A.O. 'V.Cervello', Via Trabucco,180 90146 Palermo, Italy. Fax: + 390916880828.

E-mail address: aurelio.maggio@ospedaliriunitipalermo.it (A. Maggio).
}

The prognosis for thalassemia major has dramatically improved during the last three decades [2,3]. Transfusions and the availability of different iron chelators are the main reasons for significantly increased survival and reduced morbidity in this population [4-6].

Despite these positive advances, many transfusion-dependent patients continue to develop tissue damage, mainly from tissue iron accumulation, putting them at risk of premature death, particularly from cardiac disease. Heart complications remain a major cause of 


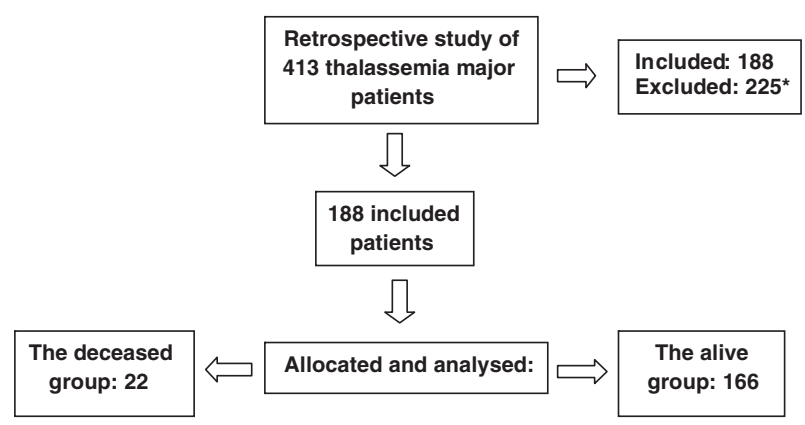

* 189 younger than 15 years of age and 36 lost at the follow-up

Fig. 1. Trial profile of the deceased group versus the alive group during the study.

mortality among patients with thalassemia major [5-7]. Specifically, cardiac failure occurs in $6-10 \%$ of these patients $[5,6,8]$.

The combination of iron-mediated toxicity [9] with increased cardiac output [10] is associated with the development of heart failure. In recent years, several methods of detecting tissue iron content have been developed [11]. Among these methods, the Cardiac Magnetic Resonance $\mathrm{T}^{*}$ parameter (CMR-T2*) [12] is a powerful predictor of the subsequent development of heart failure, especially for cardiac T2* values $<7$ ms [13]. Recently, Marsella et al. [14], studying a large cohort of thalassemia major patients, showed that only $9 \%$ of men and 3\% of women with CMR-T2* above 20 ms had cardiac dysfunction. Moreover, a statistical significant difference in CMR-T2* was shown between patients with normal and abnormal cardiac functions $(p<0.0001)$ [14].

However, the lack of worldwide availability of CMR-T2* facilities is a crucial limitation preventing its widespread use for annual follow-up evaluations of cardiac function in thalassemia major patients [15]. Actually, Thalassemia International Federation (TIF), involving an umbrella of 109 national thalassemia associations worldwide, pointed out that only 19/55 countries use the cardiac validated MRI T2* software (personal communication). This, in most of the cases, does not allow access to the majority of patients but only to a portion of the patients that are around the centers where CMR-T2* is available.

The limited availability of CMR-T2* facilities worldwide [15] warrants the more widespread adoption of effective and accessible tools for the detection of thalassemia major patients at risk of heart failure. The determination of Left Ventricular Ejection Fraction (LVEF) by echocardiography is considered to be a reliable and widely used tool to evaluate heart function. The worldwide availability of echocardiography is also greater than that of CMR-T2*. Recent studies have shown acceptable interobserver and intraobserver reproducibility values of the echocardiographic evaluation of left ventricular ejection fraction [16,17], similar to that of CMR, even in patients with thalassemia major [18]. Otterstad et al. [19] confirmed that 2-D echocardiography measurements of LVEF are more accurate and reproducible if determination is performed by a single operator, as was performed in our study. For all these reasons regular monitoring of LVEF in thalassemia major patients has been strongly recommended [20] and should be included in any service with the responsibility of care for thalassemia major patients.

The main aim of this study was to evaluate whether variations in LVEF values over time could be used as a predictive tool in the risk assessment of cardiac death in thalassemia major patients.

\section{Materials and methods}

\section{Patients}

This report describes a retrospective study of 413 patients with thalassemia major who were managed from January 31, 1980 to January 31, 2008. Age was measured as difference between death versus born year among deceased patients, while as difference between January 31, 2008 versus born year for alive patients. A complete LVEF record was defined as at least 1 complete echocardiography each year for at least four consecutive years in patients older than 15 years and without any clinical evidence of cardiac disease. Among the 413 observed patients, 188 had complete records for serial observations of LVEF measurements for at least four consecutive years (Fig. 1). The remaining patients were excluded either because they were younger than 15 years at January 31, 1980 or because they were lost at the follow-up (Fig. 1). The census for alive and not-alive group was taken during the follow-up period. The median of this was 8.5 years. All deaths considered in this study were due to cardiac disease (Table 1). The diagnosis of heart disease was based on standard clinical and instrumental findings including echocardiography and electrocardiogram [20]. Findings, reported on Table 1, refer to the year of patient's first observation. Patients that stabilize their LVEF by taking cardiac drugs or that, after an initial decrease, had a subsequent increase of LVEF are still now alive. Their LVEF improved gradually and only three are still receiving Ace-inhibitor treatment.

\section{Method}

LVEF is defined as the fraction of end-diastolic volume that is ejected by the left ventricle in each beat. It was measured by a single operator with two-dimensional (2-D) echocardiography assessments

Table 1

Findings at the start among the 188 patients included in the trial.

\begin{tabular}{|c|c|c|c|}
\hline Findings & Deceased-group $^{\mathrm{a}}$ & Alive-group & p-Value \\
\hline No pts (188) & 22 & 166 & \\
\hline Females (\%) & $11(50.00)$ & $85(51.21)$ & 0.93 \\
\hline Treatment & 1 pt Sequential DFO-DFP, 21 pts DFO & 84 pts DFO, 47 pts DFP, 35 Sequential DFO-DFP & \\
\hline Age in years & $29 \pm 7.52$ & $32 \pm 8.66$ & 0.11 \\
\hline $\mathrm{Hgb}, \mathrm{g} / \mathrm{l}^{\mathrm{a}}$ & $9.87 \pm 0.55$ & $9.08 \pm 0.81$ & 0.0005 \\
\hline ALT, IU/1 ${ }^{\mathrm{a}}$ & $71.37 \pm 36.52$ & $48.51 \pm 39.33$ & 0.0438 \\
\hline LIC, mg/g/dw & $7272.5 \pm 11,107.74$ & $3014.58 \pm 3257.67$ & 0.0329 \\
\hline Total blood transfusion, $\mathrm{ml} / \mathrm{kg} /$ year & $9007.18 \pm 2169.16$ & $8829.55 \pm 2471.06$ & 0.782 \\
\hline Mean ferritin, $\mu \mathrm{g} / \mathrm{l}$ & $2413.5 \pm 1497.12$ & $1505.95 \pm 785.53$ & $<0.0001$ \\
\hline Mean basal LVEF< $55 \%$ (no) & $46.78 \pm 7.32(9)$ & $47.52 \pm 8.74(19)$ & 0.945 \\
\hline Mean age at DFO starting, years & $8.68 \pm 1.14$ & $5.54 \pm 0.41$ & 0.017 \\
\hline Splenectomy (\%) & $16(72.72)$ & $72(43.37)$ & 0.0336 \\
\hline Cirrhosis (\%) & $8(36.36)$ & $9(5.42)$ & 0.11 \\
\hline Arrhythmia (\%) & $10(45.45)$ & $23(13.85)$ & 0.0489 \\
\hline HCV-RNA positive (\%) & $15(68.18)$ & $47(28.31)$ & 0.0056 \\
\hline
\end{tabular}

\footnotetext{
a All patients died for cardiac diseases, particularly, 19 for left heart failure, 2 for right heart failure and 1 for arrhythmia due to ventricular fibrillation.
} 


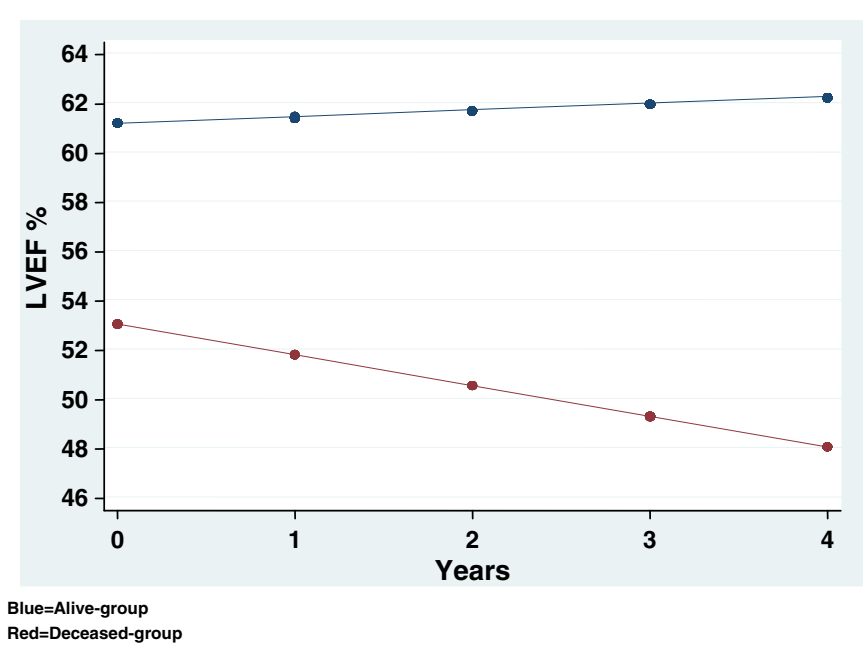

Fig. 2. Estimated profiles from the fitted GEE model for the two patient-groups: the deceased versus the alive-group.

dividing the stroke volume by the end-diastolic volume in each patient (Vivid S5, Gems Ultrasound, Tirat Carmel, Israel).

Two-dimensional echocardiography was used for determination of the left ventricular ejection fraction and volumes (single plane arealength method), and for calculation of right ventricular end-diastolic and end-systolic areas by planometry from the four-chamber view, according to previous recommendations [21]. Patient baseline clinical findings were reported with means and standard deviations (SD) for continuous variables and as proportions for dichotomous variables. LIC was determined on liver biopsies by atomic spectrophotometer. Liver biopsy was performed only in patients included in interferon treatment for chronic $\mathrm{C}$ hepatitis.

\section{Statistical models}

The generalized estimating equations (GEE) model was used [22] to evaluate if the variation of LVEF over time (four consecutive years) was statistically significant different between alive versus not alive patients.

Actually, LVEF values consisted of repeated observations over time on the same patient. These measurements, taken on the same patient, may not be independent one from another. In this context, one of the appropriate models, taking into account for the issue that repeated measurements might be correlated, is the generalized estimating equations (GEE) model [22], which results to be more reliable in comparison with evaluation of single temporal finding by Student $t$ test. In the GEE model, status-effect (status), time-effect (time) and status-by-time interaction effect (status $\times$ time) were considered. This approach was implemented using the 'xtgee' procedure in the Stata 11 software (Stata Corporation, College Station, TX, USA).

Because the GEE model pointed out a statistically significant difference in the variation of LVEF over time between alive versus not alive patients (Fig. 2, Table 3), a logistic regression model was used to evaluate the risk of death from heart disease on the basis of the mean variations in LVEF (Table 4). Therefore, the mean variations in LVEF values were categorized into three levels: 1) the baseline category, including all patients with an increase in mean of $\mathrm{LVEF} \geq 0 \% ; 2$ ) the 1-category, including all patients with a reduction in mean of LVEF between $0 \%$ and $7 \%$; and 3 ) the 2-category, including all patients with a reduction in mean LVEF $\geq 7 \%$ (Table 2 ). The choice of $7 \%$ was based on a paper by Kalogeropoulos et al. [23], which assessed LVEF determination using 2-D echocardiography and suggested $7 \%$ as the amount of variability for test-retest measurement with a 95\% agreement. ROC curve was used for assessing a prognostic value of $\delta$ LVEF, calculated as the difference between the initial and final values of LVEF [24]. The sensitivity and specificity of delta LVEF, based for values of $\operatorname{LVEF} \geq 7 \%$, were also calculated [24]. Survival curves among baseline, 1-category and 2-category were estimated using the Kaplan-Meier method and the survival among groups were compared with the log-rank test [24]. All of the statistical analyses were performed by A.V.

\section{Results}

Demographic findings of patients in both groups are shown in Table 1 . Among the 188 analyzed patients, 166 were alive. Among the 22-deceased cohort, 21 patients were being treated with deferoxamine alone treatment (DFO), while 1 received sequential treatment of deferoxamine (DFO) and deferiprone (DFP) (Table 1) [25]. In the alive cohort 84 patients received DFO-alone, 47 DFP-alone and 35 DFODFP-sequential chelation treatment regimens (Table 1). The number of patients with a mean basal $\mathrm{LVEF}<55 \%$ was not statistically different between the two groups (Table 1). On the other hand, patients in the deceased cohort had statistically significant higher LIC and serum ferritin levels compared with the alive group (Table 1). Moreover, a statistically significant difference was found between the two groups regarding mean levels of $\mathrm{Hb}(\mathrm{g} / \mathrm{l})$, mean age at starting chelation treatment, splenectomy, arrhythmia (\%) and HCV-RNA positivity (\%) (Table 1). The deceased, included in this trial, died for heart disease (Table 1). The proportions of patients in the alive and deceased cohorts, categorized into the three LVEF categorized groups are shown in Table 2. Fig. 2 shows

Table 2

Findings found after categorizing the average changing of LVEF in three different levels (baseline, 1 and 2) a

\begin{tabular}{|c|c|c|c|c|c|c|c|c|c|}
\hline \multirow[t]{2}{*}{ Findings } & \multicolumn{3}{|l|}{ Baseline } & \multicolumn{3}{|l|}{ 1-Category } & \multicolumn{3}{|l|}{ 2-Category } \\
\hline & Deceased-group & Alive-group & p-Value & Deceased-group & Alive-group & p-Value & Deceased-group & Alive-group & p-Value \\
\hline No pts (188) & 5 & 77 & & 6 & 61 & & 11 & 28 & \\
\hline Females (\%) & $2(20)$ & $37(48.1)$ & 0.44 & $4(66.6)$ & $37(0.6)$ & 0.81 & $5(45.5)$ & $11(0.39)$ & 0.82 \\
\hline Age in years & $28.6 \pm 9.1$ & $31.8 \pm 10$ & 0.48 & $31.6 \pm 7.9$ & $31.3 \pm 7.3$ & 0.89 & $27.5 \pm 6.8$ & $34.1 \pm 7.0$ & 0.0124 \\
\hline $\mathrm{Hgb}, \mathrm{g} / \mathrm{l}^{\mathrm{a}}$ & $9.6 \pm 0.4$ & $9.03 \pm 0.7$ & 0.18 & $9.8 \pm 0.6$ & $8.9 \pm 0.7$ & 0.01 & $10.1 \pm 0.6$ & $9.4 \pm 1.0$ & 0.13 \\
\hline $\mathrm{ALT}, \mathrm{IU} / \mathrm{l}^{\mathrm{a}}$ & $65.8 \pm 37.3$ & $44.1 \pm 38.5$ & 0.24 & $94.4 \pm 64.3$ & $56.9 \pm 44.2$ & 0.11 & $94.7 \pm 47.6$ & $42.5 \pm 29.2$ & 0.0016 \\
\hline Total blood transfusion, $\mathrm{ml} / \mathrm{kg} /$ year & $\begin{array}{l}7408.3 \pm \\
21,764.3\end{array}$ & $\begin{array}{l}8196.7 \pm \\
2392.2\end{array}$ & 0.58 & $10,575 \pm 2467.6$ & $\begin{array}{l}9035.1 \pm \\
2336.3\end{array}$ & 0.21 & $8843.3 \pm 1882.3$ & $\begin{array}{l}10,154.3 \pm \\
2462.1\end{array}$ & 0.15 \\
\hline Mean ferritin, $\mu \mathrm{g} / \mathrm{l}$ & $1887.6 \pm 1499.3$ & $1548.7 \pm 687.4$ & 0.35 & $1985.6 \pm 1508.8$ & $1728.9 \pm 963.2$ & 0.6 & $2890.4 \pm 1555.7$ & $1549.2 \pm 694.8$ & 0.0022 \\
\hline Basal mean ejection fraction & $45.6 \pm 10.5$ & $56.9 \pm 7.7$ & 0.025 & $60 \pm 2.2$ & $63.7 \pm 5.4$ & 0.09 & $55.9 \pm 8.1$ & $71.5 \pm 5.6$ & $<0.0001$ \\
\hline Mean age at DFO starting, years & $10.2 \pm 2.5$ & $6.1 \pm 5.9$ & 0.16 & $8.5 \pm 7.2$ & $4.7 \pm 3.6$ & 0.06 & $8 \pm 4.3$ & $5.9 \pm 4.4$ & 0.25 \\
\hline Splenectomy (\%) & $3(60)$ & $35(45.4)$ & 0.61 & $3(60)$ & $27(46.5)$ & 0.64 & $10(27.1)$ & $10(90.9)$ & 0.0037 \\
\hline Cirrhosis (\%) & $1(20)$ & $5(6.5)$ & - & $1(20)$ & $2(3.4)$ & - & $4(40)$ & $2(7.1)$ & 0.4026 \\
\hline Arrhythmia (\%) & $3(60)$ & $13(16.8)$ & 0.11 & $2(20)$ & $6(9.8)$ & 0.7 & $5(45.5)$ & $4(14.3)$ & 0.3173 \\
\hline HCV-RNA positive (\%) & $3(60)$ & $17(22.6)$ & 0.18 & $3(60)$ & $21(35)$ & 0.4 & $9(81.8)$ & $9(32.1)$ & 0.0332 \\
\hline
\end{tabular}

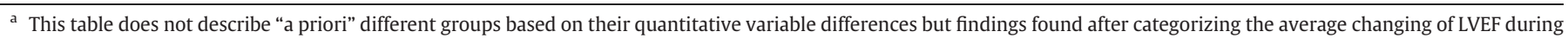
the time. 
Table 3

GEE model to evaluate changes in mean ejection fraction levels in deceased-group versus alive-group over time.

\begin{tabular}{lclc}
\hline & Coefficients $\left(\mathrm{SE}^{*}\right)$ & $95 \% \mathrm{Cl}^{*}$ & $\mathrm{p}$-Value \\
\hline Intercept & $60.89(0.61)$ & $(59.69 ; 62.09)$ & $<0.0001$ \\
Status $^{* *}$ & $-6.58(1.78)$ & $(-10.08 ;-3.07)$ & $<0.0001$ \\
Year $^{* *}$ & $0.27(0.13)$ & $(-0.001 ; 0.54)$ & 0.051 \\
Status $^{*}$ year $^{* *}$ & $-1.51(0.41)$ & $(-2.31 ;-0.71)$ & $<0.0001$ \\
\hline
\end{tabular}

$\mathrm{SE}^{*}=$ Standard Error, $\mathrm{Cl}^{*}=$ Confidence Interval, $\mathrm{p}$-value ${ }^{*}$ from null hypothesis coefficient $=0$ by Wald's test.

Status $^{* *}$ is the variable indicating if a patient is dead or alive; Year ${ }^{* *}$ is the variable indicating the consecutive years of observation, corresponding to $t=0,1,2,3,4$; Status $\times$ Year $^{* *}$ is a status-by-time interaction effect.

the profiles of estimated mean LVEF values between the two groups based on the fitted GEE model. The regression coefficient of status $\times$ year suggested a statistically significant linear decrease over time of LVEF values among the deceased patients (Coeff. -1.51 , 95\% CI $(-2.31-$ 0.71 ), p-value $<0.0001$, Table 3 and Fig. 2) compared with the alive ones. Actually, the alive cohort had increased LVEF values over time, although this result determination in detecting was not statistically significant (Coeff. 0.27, 95\% CI ( $-0001 ; 0.54)$, p-value $=0.051$, Table 3 and Fig. 2). The risk of death due to cardiac failure in patients with a mean reduction of $L V E F \geq 7 \%$ was 4.93 , with a $95 \%$ confidence interval $(C I)$ of 1.61 to 15.11 ( $p$-value $=0.005$, Table 4 ). The median time from the last echocardiography to death was 3 years. Falls in LVEF between $0 \%$ and $7 \%$ were not associated with statistically significant risk of death for heart disease $(\mathrm{OR}=1.22$, $\mathrm{p}$-value $=0.762$, Table 4$)$. No statistically significant correlation was found between the $\delta$ LVEF and serum ferritin levels $(\mathrm{r}=-0.11 ; \mathrm{p}=0.22$ ). The area under the ROC curve was $70.33 \%$ (Fig. 3 ). The sensitivity and specificity of $\delta$ LVEF were $84.76 \%$ and $40.91 \%$, respectively (Fig. 3). Fig. 4 shows the Kaplan-Meier survival curves concerning the three considered different categories of thalassemia major patients. Finally, to see if LVEF represented a stronger prognostic marker than other laboratory and instrumental variables, a multivariate analysis at baseline for LVEF at baseline, serum ferritin levels and LIC was performed. All these variables were matched with probability of death. No statistically significant result was obtained by this analysis.

\section{Discussion}

These findings suggest a reduction in $\mathrm{LVEF} \geq 7 \%$, over time, determined by 2-D echocardiography, may be considered a strong predictive tool for the detection of thalassemia major patients with increased risk of death due to cardiac disease (Fig. 2, Table 3). Moreover, the reduction in $\mathrm{LVEF} \geq 7 \%$ showed high sensitivity $(84.76 \%$ ) in predicting increased risk of death due to cardiac disease (Fig. 3). Finally, as it is shown by the Kaplan-Meier survival curves (Fig. 4), thalassemia major patients included in category 2 showed a statistically significant decrease of survival probability for cardiac disease in comparison with baseline

Table 4

Logistic regression model indicated an effect of the mean reduction of ejection fraction on risk of death for heart disease.

\begin{tabular}{llll}
\hline & OR $^{*}\left(\mathrm{SE}^{*}\right)$ & $95 \% \mathrm{Cl}^{*}$ & p-Value \\
\hline MVLVEF1 $^{* *}$ & $1.22(0.81)$ & $(0.33 ; 4.41)$ & 0.762 \\
MVLVEF2 $^{* *}$ & $4.93(2.81)$ & $(1.61 ; 15.11)$ & 0.005 \\
\hline
\end{tabular}

$\mathrm{OR}^{*}=$ Odds Ratio, $\mathrm{SE}^{*}=$ Standard Error, $\mathrm{Cl}^{*}=$ Confidence Interval.

MVLVEF1 $^{* *}$ is the 1-category of the mean variation of LVEF variable including all patients with a mean reduction of ejection fraction greater than $0 \%$ and less than $7 \%$. MVLVEF2 ${ }^{* *}$ is the 2-category of the mean variation of LVEF variable including all patients with a mean reduction of ejection fraction greater or equal to $7 \%$.

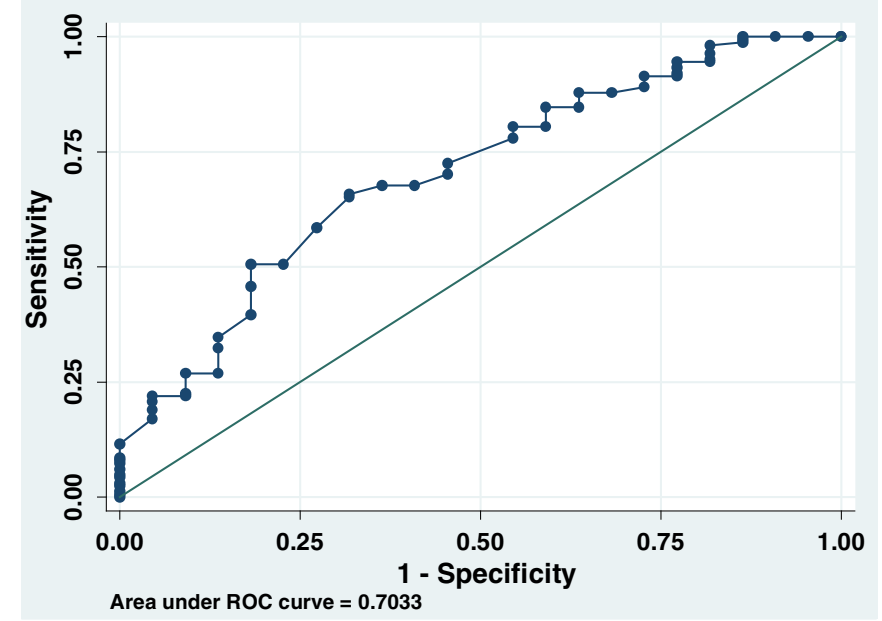

Fig. 3. ROC curve showing sensitivity and specificity of $\delta$ LVEF in detecting TM patients at risk of death for cardiac disease.

and 1 -category group, respectively $(\mathrm{p}=0.0022)$. The detection of $2 / 22$ deaths from right ventricular failure (Table 1) could be explained by the presence, in these patients, of a biventricular cardiomyopathy, reported on thalassemia major patients [26]. Moreover, sudden arrhythmic death is recognized as the cause of death in from 30\% to $50 \%$ of patients with heart failure. Furthermore, it has been demonstrated that implantation of ICD (Intracardiac Defibrillator) is effective in reducing mortality through prevention of sudden arrhythmic death, in patients with mild or moderate dysfunction (II or III NYHA class) [27]. This could be the reason for the single death due to ventricular fibrillation among our patients (Table 1 ). The mean of LVEF at 1 year from the follow-up in patients with $>7 \%$ change in LVEF was $63 \pm 3 \%$.

Relying on LVEF values in the management of heart failure in thalassemia major patients has been stressed in several previous papers. Davis et al. [28] reported findings concerning eighty-one patients with thalassemia major but no history of cardiac disease who received quantitative annual LVEF monitoring by radionuclide ventriculography using multigated acquisition (MUGA) for a median of 6.0 years (inter-quartile range, 2-12 years) [28]. An absolute LVEF decrease of more than 10 percentage units was significantly associated with subsequent development of symptomatic cardiac disease $(\mathrm{p}<.001)$ and death $(\mathrm{p}=.001)$, with a median interval between the first abnormal LVEF findings and

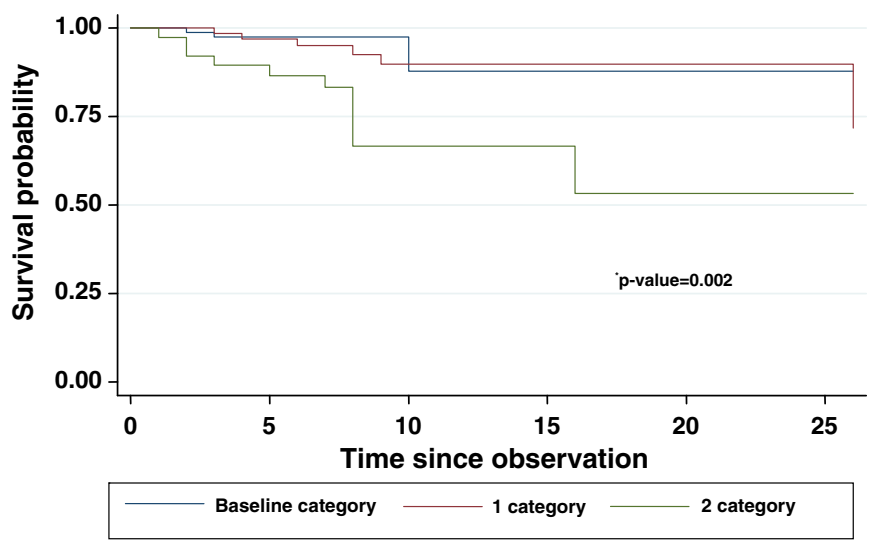

${ }^{*} \mathrm{p}$-value from log-rank test

Fig. 4. Kaplan-Meier curves for cardiac disease mortality in the three categorized thalassemia major groups. 
the development of symptomatic heart disease of 3.5 years, similar to what was found in this paper [28]. Moreover, Davis et al. [28] reported that LVEF changes were demonstrable before cardiac symptoms appeared in all patients except 1 [28]. Furthermore, studies reporting on the use of chelators in treating transfusional iron overload have raised interesting questions regarding cardiac performance associated with changes in mean LVEF values of thalassemia major patients. Studies of thalassemia major patients during heart failure with severe cardiac siderosis and decreased LVEF have shown that a combined treatment of deferiprone and deferoxamine increased mean absolute cohort LVEF values by $14 \%$ over 1 year [29], while treatment with continuous intravenous deferoxamine raised LVEF by $11 \%$ [30]. Recently, Pennell et al. [31] hypothesized that small increases in LVEF among thalassemia major patients would be expected to reduce the risk of heart failure. Changes in LVEF (3.1\% vs. 2.6\%), as compared with CMR-T2* during DFP-alone or combination DFP-DFO treatment, were associated with risk reduction for the development of heart failure over 12 months ( $46.4 \%$ vs. $25.5 \%$, respectively) [31]. However, the actual risk for heart failure, in this paper, remains very small. Recently, a multicenter randomized open-label long-term sequential deferiprone-deferoxamine (DFP-DFO) versus DFP alone trial, performed in patients with thalassemia major, was retrospectively reanalyzed to assess the variation in the LVEF [32]. The DFP-alone group showed statistically significant increase over time in mean LVEF in comparison with sequential DFO-FP treatment (coefficient 0.97, 95\% CI $(0.51 ; 1.44)$, p-value $<0.0001)$ [32]. These findings, obtained by 2D-echocardiography assessment [30] are very similar to those reported by Pennell et al. [31] using CMR-T2*.

Although the use of CMR-T2* has a main role in managing thalassemia major, the limited availability of CMR-T2* facilities worldwide [15] warrants the more widespread adoption of effective and accessible tools for the detection of thalassemia major patients at risk of cardiac disease. As it is well known, the worldwide availability of echocardiography is greater. Although, concerns remain regarding the reliability of echocardiography in determining LVEF [16-20], the use of echocardiographic equipment with advanced technology in combination with implementation of harmonic imaging may enhance detection of endocardial borders with more accurate determination of LVEF [33].

In conclusion, this retrospective survey suggests that variations in LVEF values over time, as determined by 2D-echocardiography, may be used for risk assessment of heart failure in patients with thalassemia major. However, because of limitations related to the study design, such findings should be confirmed in a large long-term prospective clinical trial.

\section{Author's contributions}

$\mathrm{AM}$ and $\mathrm{AV}$ were the principal investigators and take primary responsibility for this paper. AM, AV and GL wrote the paper. AV performed the statistical analysis. AE, MA, HH, PT, JMW, AP, and NC criticized and improved the paper. The remaining authors are responsible for the patients' clinical management. The authors report no potential conflicts of interest.

\section{Conflict of interest}

The authors declare no competing financial interests.

\section{Acknowledgments}

We thank the following people for their collaboration: Dr. L. Cuccia, Dr. F. Gagliardotto (U.O.C. Centro di Prevenzione Diagnosi e Cura della Talassemia, ARNAS Civico, Di Cristina, Benfratelli, Palermo), Dr. Michele Rizzo (U.O.C. Ematologia, A.O. S. Elia, Caltanissetta), Dr. G. D'Ascola (Centro Microcitemia, A.O. B.M.M., Reggio Calabria), Dr. A. Ciancio (Ospedale Civile Madonna delle Grazie, U.O. Talassemia, Matera), and Dr. R. Barone (Dottorato di Ricerca in Biotecnologie Chirurgiche e
Medicina Rigenerativa, Università di Palermo). This paper was partially supported by Foundation Franco and Piera Cutino.

\section{References}

[1] D.R. Higgs, J.D. Engel, G. Stamatoyannopoulos, Thalassemia, Lancet 379 (2012) 373-383.

[2] C. Borgna-Pignatti, S. Bertelli, Morbidity and life expectancy in patients with thalassemia major and intermedia, Eur. J. Clin. Med. Oncol. 3 (2011) 1.

[3] P. Telfer, Update on survival in thalassemia major, Hemoglobin 33 (Suppl. 1) (2009) S76-S80.

[4] B. Modell, M. Khan, M. Darlison, Survival in beta-thalassemia major in the UK: data from the UK Thalassemia Register, Lancet 355 (2000) 2051-2052.

[5] C. Borgna-Pignatti, S. Rugolotto, P. De Stefano, H. Zhao, M.D. Cappellini, G.C. Del Vecchio, M.A. Romeo, G.L. Forni, M.R. Gamberini, R. Ghilardi, A. Piga, A. Cnaan, Survival and complications in patients with thalassemia major treated with transfusion and desferrioxamine, Haematologica 89 (2004) 1187-1193.

[6] V. Ladis, G. Chouliaras, V. Berdoukas, P. Moraitis, E. Berdoussi, C. Kattamis, Relation of chelation regimes to cardiac mortality and morbidity in patients with thalassaemia major: an observational study from a large Greek Unit, Eur. J. Haematol. 85 (2010) 335-344.

[7] V. Gabutti, A. Piga, Results of long-term iron-chelating therapy, Acta Haematol. 95 (1996) 26-36.

[8] M.J. Cunningham, E.A. Macklin, E.J. Neufeld, A.R. Cohen, Complications of beta-thalassemia major in North America, Blood 104 (2004) 34-39.

[9] C.J. Murphy, G.Y. Oudit, Iron-overload cardiomyopathy: pathophysiology, diagnosis, and treatment, J. Card. Fail. 16 (2010) 888-900.

[10] A. Aessopos, V. Berdoukas, M. Tsironi, The heart in transfusion dependent homozygous thalassaemia today - prediction, prevention and management, Eur. J. Haematol. 80 (2008) 93-106

[11] J.C. Wood, Diagnosis and management of transfusion iron overload: the role of imaging, Am. J. Hematol. 82 (12 Suppl.) (2007) 1132-1135.

[12] L.J. Anderson, S. Holden, B. Davis, E. Prescott, C.C. Charrier, N.H. Bunce, D.N, Firmin, B. Wonke, J. Porter, J.M. Walker, D.J. Pennell, Cardiovascular T2-star $\left(\mathrm{T} 2^{*}\right)$ magnetic resonance for the early diagnosis of myocardial iron overload, Eur. Heart J. 22 (2001) 2171-2179.

[13] P. Kirk, M. Roughton, J.B. Porter, J.M. Walker, M.A. Tanner, J. Patel, D. Wu, J. Taylor, M.A. Westwood, L.J. Anderson, D.J. Pennell, Cardiac T2* magnetic resonance for prediction of cardiac complications in thalassemia major P, Circulation 120 (2009) 1961-1968.

[14] M. Marsella, C. Borgna-Pignatti, A. Meloni, V. Caldarelli, M.C. Dell'Amico, A. Spasiano, L. Pitrolo, E. Cracolici, G. Valeri, V. Positano, M. Lombardi, A. Pepe, Cardiac iron and cardiac disease in males and females with transfusion-dependent thalassemia major: a T2* magnetic resonance imaging study, Haematologica 96 (2011) 515-520.

[15] A.A. Ademola, An appraisal of the cost benefit of magnetic resonance imaging in Nigeria, Nigerian Postgrad. Med. J. 10 (2003) 251-253.

[16] K. Shahgaldi, P. Gudmudson, A. Manouras, L.A. Brodin, R. Winter, Visually estimated ejection fraction by two dimensional and triplane echocardiography is closely correlated with quantitative ejection fraction by real-time three dimensional echocardiography, Cardiovasc. Ultrasound 25 (2009) 41.

[17] D.S. Blondheim, R. Beeri, M. Feinberg, M. Vaturi, S. Shimoni, W. Fehske, A. Sagie, D. Rosenmann, P. Lysyansky, L. Deutsch, M. Leitman, R. Kuperstein, I. Hay, D. Gilon, Z. Friedman, Y. Agmon, Y. Tsadok, N. Liel-Cohen, Reliability of visual assessment of global and segmental left ventricular function: a multicenter study by the Israeli Echocardiography Research Group, J. Am. Soc. Echocardiogr. 23 (2010) 258-264.

[18] A. Giakoumis, V. Berdoukas, E. Gorsis, A. Aessopos, Comparison of echocardiographic (US) volumetry with cardiac magnetic resonance (CMR) imaging in transfusion ependent thalassemia major (TM), Cardiovasc. Ultrasound 5 (2007) 24

[19] J.E. Otterstad, G. Froeland, M. St John Sutton, I. Holme, Accuracy and reproducibility of biplane two-dimensional echocardiographic measurements of left ventricular dimensions and function, Eur. Heart J. 18 (1997) 507-513.

[20] T. Cogliandro, G. Derchi, L. Mancuso, B. Pannone, A. Pepe, M. Pili, P. Bina, P. Cianciulli, V. De Sanctis, A. Maggio, Guideline recommendations for heart complications in thalassemia major, J. Cardiovasc. Med. (Hagerstown) 9 (2008) 515-525.

[21] N.B. Schiller, P.M. Shah, M. Crawford, Recommendations for quantitation of the left ventricle by two-dimensional echocardiography. American Society of Echocardiography Committee on Standards. Subcommittee on Quantitation of Two-dimensional Echocardiograms, J. Am. Soc. Echocardiogr. 2 (1989) 358-367.

[22] D. Hedeker, R.D. Gibbons, Longitudinal Data Analysis, Hoboken Wiley, New Jersey, 2006.

[23] A.P. Kalogeropoulos, V.V. Georgiopoulou, M. Gheorghiade, J. Butler, Echocardiographic evaluation of left ventricular structure and function: new modalities and potential applications in clinical trials, J. Card. Fail. 18 (2012) 159-172.

[24] D. Collett, Modelling Binary Data, Chapman \& Hall, Boca Raton, 2003.

[25] A. Maggio, A. Vitrano, M. Capra, L. Cuccia, et al., Long-term sequential deferiprone-deferoxamine versus deferiprone alone for thalassaemia major patients: a randomized clinical trial, Br. J. Haematol. 145 (2009) 245-254.

[26] G. Hahalis, D. Alexopulos, D.T. Kremastinos, N.C. Zoumbos, Heart failure in beta-thalassemia syndromes: a decade of progress, Am. J. Med 118 (2005) 957-967.

[27] L.J. Gula, G.J. Klein, A.S. Helcamp, D. Massel, et al., Ejection fraction assessment and survival: an analysis of the Sudden Cardiac Death in Heart Failure Trial (SCD-HeFT), Am. Heart J. 156 (2008) 1196-1200. 
[28] B.A. Davis, C. O'Sullivan, P.H. Jarritt, J.B. Porter, Value of sequential monitoring of left ventricular ejection fraction in the management of thalassemia major, Blood 104 (2004) 263-269.

[29] M.A. Tanner, R. Galanello, C. Dessi, G.C. Smith, M.A. Westwood, A. Agus, M. Pibiri, S.V. Nair, J.M. Walker, D.J. Pennell, Combined chelation therapy in thalassemia major for the treatment of severe myocardial siderosis with left ventricular dysfunction, J. Cardiovasc. Mag. Res. 10 (2008) 12.

[30] L.J. Anderson, M.A. Westwood, S. Holden, B. Davis, E. Prescott, B. Wonke, J.B. Porter, J.M. Walker, D.J. Pennell, Myocardial iron clearance during reversal of siderotic cardiomyopathy with intravenous desferrioxamine: a prospective study using T2* cardiovascular magnetic resonance, Br. J. Haematol. 127 (2004) 348-355.
[31] D.J. Pennell, J.P. Carpenter, M. Roughton, Z. Cabantchik, On improvement in ejection fraction with iron chelation in thalassemia major and the risk of future heart failure, J. Cardiovasc. Mag. Res. 13 (2011) 45-53.

[32] A. Maggio, A. Vitrano, G. Lucania, M. Capra, L. Cuccia, et al., Long-term use of deferiprone significantly enhances left-ventricular ejection function in thalassemia major patients, Am. J. Haematol. 87 (2012) 732-733.

[33] R.M. Lang, M. Biering, R.B. Devereux, F.A. Flachskampf, E. Foster, et al., Recommendations for chamber quantification: a report from the American Society of Echocardiography's Guidelines and Standard Committee and the Chamber Quantification Writing Group, developer in conjunction with the European Association of Echocardiography, a branch of the European Society of Cardiology, J. Am. Soc. Echocardiogr. 18 (2005) 1440-1463. 